\title{
THE DEFORMATION OF AZ31 MAGNESIUM ALLOY DURING WARM CONSTRAINED GROOVE PRESSING
}

\author{
Hue Thi Hong Dang ${ }^{1)}$, Pham Thi Thuy ${ }^{2)}$, Dao Minh Ngung ${ }^{1)}$, Pham Quang ${ }^{1)^{*}}$, Valery Y. \\ Shchukin ${ }^{3)}$ \\ 1) Hanoi University of Science and Technology, No.1 Daicoviet, Hanoi, Vietnam \\ 2) Hanoi University of Mining and Geology, 18 Phovien, Bac Tu Liem, Hanoi, Vietnam \\ 3) Belarusian National Technical University, Belarus
}

Received: 17.01.2019

Accepted: 26.02.2019

${ }^{*}$ Corresponding author: e-mail: quang.pham@hust.edu.vn Tel.: +84 888039303, Hanoi

University of Science and Technology, No.1 Daicoviet, Hanoi, Vietnam

\begin{abstract}
A magnesium alloy AZ31 as plate of dimensions $(60 \times 60 \times 3) \mathrm{mm}$ has been constrained groove pressed (CGP) four deformation passes (16 pressings) at $250{ }^{\circ} \mathrm{C}$ by simulation and experiments. On the basis of the analysis of calculation results about the deformation distribution in the alloy AZ31 workpieces, the mechanism for its microstructure evolution during the severe plastic deformation (SPD) process was partly clarified. On the other hand, deformation heterogeneity distribution developed in the workpieces by applying CGP caused the evolution of a non-uniform microstructure. The TEM microstructure analysis results provided clear evidence that across the plate both the banded deformed microstructure where dislocation cell structure and/or partially or fully recovered polygonized subgrain microstructure are present. The recovering dynamic and local polygonization process contributes significantly to the formation of ultra-fine materials (UFG) microstructure.
\end{abstract}

Keywords: Finite Element Simulation, SPD, Constrained Grooved Pressing, AZ31 Magnesium Alloys, TEM

\section{Introduction}

Magnesium alloy is considered as an advanced material for many applications, especially in automotive, rail and aviation industries, with a low density advantage $\left(1.74 \mathrm{~g} / \mathrm{cm}^{3}\right)$ and high thermal conductivity [1-3]. However, the morphology of the alloy is poor at room temperature because the crystalline lattice structure is tightly bound (h.c.p.), leading to limited deformability $[4,5]$. However, the process of deformation by rolling, forging, pressing and polishing is still easy thanks to the mechanism of the mate and the operation of the slider at temperatures above $200{ }^{\circ} \mathrm{C}$. During last decade, severe plastic deformation has been regarded as a viable method for producing nanostructured or ultra-fine materials [6-9]. Several methods have been proposed, developed and researched [10-12].

A severe plastic deformation method with great potential for the production of ultra-fine materials has been developed as a CGP $[13,14]$. In 2001, Zhu undertook a SPD method based on the method of squeezing a flat metal plate with a cyclic groove die and then restoring the original planar shape to the flat die. Repetition of this process repeatedly causes large plastic deformation to accumulate in the sample without significantly altering the initial size (Fig. 1). 

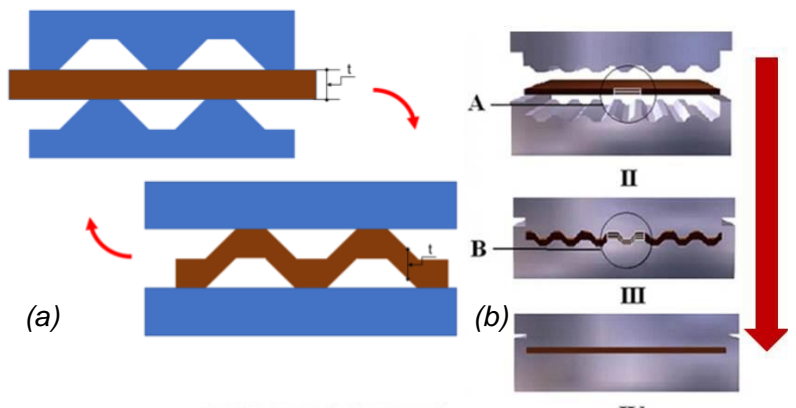

(a)

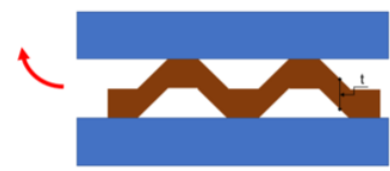

IV

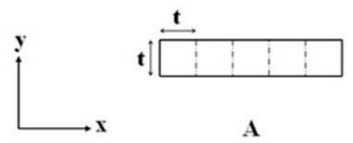

(c)

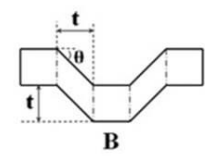

Fig. 1 Schematic representation of CGP process

The amount of plastic strain is dependent on the number of times and die geometry such as groove angle under the plane strain shear deformation using the equation (1.) of effective strain [18].

$\varepsilon=n \frac{4}{\sqrt{3}} \ln \left(\frac{r+t}{r+0.5 t}\right)$ with $r=\frac{t}{\sin \theta}$

where, $\mathrm{n}$ is the number of time, $\mathrm{t}$ is the thickness of the workpiece and $\theta$ is the groove angle.

The variation of the groove angle of the die to changes in the deformation level of the workpiece. Effective strain $\left(\varepsilon_{\text {eff }}\right)$ is calculated by the equation [14].

$\varepsilon_{\text {eff }}=\frac{\tan \theta}{\sqrt{3}}$

\section{Experimental materials and FEM methods}

Although some experimental SPD and numerical simulation studies have been carried out on materials such as steel, copper, pure aluminum [15-18], but little is studying in the CGP publication.

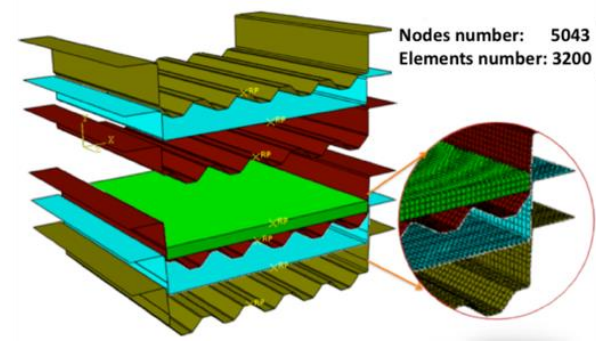

Fig. 2 Die and workpiece used in FEM Fig. 3 Designed grooved die (a), flat die (b) simulation

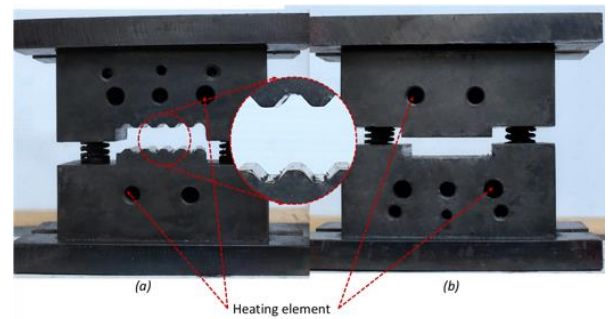

ABAQUS software [19] was used in this study. On the basis of the size of the billet, the size of the mold, the mold and the detailed parts were calculated preliminary for the experiment. The 
geometry of the 3D is driven directly on software Abaqus (Fig. 2). Abaqus offers several models for metal plasticity analysis. Main options include a choice between rate-independent and ratedependent plasticity, a choice between the Mises yield surface for isotropic materials and Hill's yield surface for anisotropic materials. This decomposition can be used directly to formulate the plasticity model. Historically, an additive strain rate decomposition is:

$\dot{\varepsilon}=\dot{\varepsilon}^{e l}+\dot{\varepsilon}^{p l}$

Here $\dot{\varepsilon}$ is the total (mechanical) strain rate, $\dot{\varepsilon}^{e l}$ is the elastic strain rate, and $\dot{\varepsilon}^{p l}$ is the plastic strain rate. This is intended for relatively high strain rate applications, such as dynamic events or metal forming process simulations. This type of rate dependence can be introduced in different ways. One way is to use an overstress power law [20]:

$\dot{\bar{\varepsilon}}^{p l}=D\left(\frac{\bar{\sigma}}{\sigma^{0}}-1\right)^{n} \quad$ for $\quad \bar{\sigma} \geq \sigma^{0}$

where $\dot{\bar{\varepsilon}}^{p l}$ is the equivalent plastic strain rate; $\bar{\sigma}$ is the yield stress at nonzero plastic strain rate; $\sigma^{0}\left(\varepsilon^{p l}, \theta, f_{i}\right)$ is the static yield stress (which may depend on the plastic strain $\left(\varepsilon^{p l}\right)$ via isotropic hardening, on the temperature $(\theta)$ and on other field variables, $\left(f_{i}\right)$; and $D\left(\theta, f_{i}\right), n\left(\theta, f_{i}\right)$ are material parameters that can be functions of temperature and, possibly, of other predefined state variables.

The simulation the plate with geometry of $(60 \times 60 \times 3) \mathrm{mm}$ was modeled with total number of 3200 (CPE4RT) elements. The temperature of the workpiece and die are considered constant and equal to $250{ }^{\circ} \mathrm{C}$. The pressing speed and coefficient of friction between the die and workpiece were taken to be $35 \mathrm{~mm} / \mathrm{s}$ and 0.1 respectively. In the exprimental study magnesium alloy AZ31 commercial plates with dimensions of $(60 \times 60 \times 3) \mathrm{mm}$ were pressed up to 8 times using CGP approach. The chemical composition of the AZ31 is shown in Table 1. Before pressing, the specimen of AZ31 was annealed at $350{ }^{\circ} \mathrm{C}$ for $1 \mathrm{hr}$.

Table 1 The chemical composition of the AZ31

\begin{tabular}{|c|c|c|c|c|c|c|c|c|c|}
\hline Element & $\mathrm{Mg}$ & $\mathrm{Al}$ & $\mathrm{Si}$ & $\mathrm{Ca}$ & $\mathrm{Mn}$ & $\mathrm{Fe}$ & $\mathrm{Ni}$ & $\mathrm{Cu}$ & $\mathrm{Zn}$ \\
\hline Weight \% & 95.55 & 2.88 & 0.07 & 0.18 & 0.35 & 0.12 & 0.13 & 0.09 & 0.63 \\
\hline
\end{tabular}

Fig. 3 is shown the designed grooved die with $\theta=45^{\circ}$ (top) and the designed flat (bottom). The material selected for die is SKD61 with heat treatment. The temperature selected on the die and sample during the CGP is $250{ }^{\circ} \mathrm{C}$. The lubricant used in the experimental was $\mathrm{MoS}_{2}$. The whole pressing operation was carried out using a 100 ton hydraulic pressing machine. After straightening, the specimen is rotated $180^{\circ}$ around the axis perpendicular to the plane of the sheet and then the first stage is repeated (Fig. 1(III)).

The specimen for transmission electron microscopy (TEM) were then selected from pressed plates, in order to evaluate the effect of straining on microstructure development. The selection of samples after the 8 deformation passes (16 pressings) were done from the top of the groove, which relates to an "undeformed" region (1), and from the inclined region, which relates to a sheared area, where equivalent strain of $\varepsilon \sim 4.5$ was achieved ( 2 and 3 ), is shown in Fig. 5 (a).

\section{Results and Discusion}

In the equation 1 , with $\theta=45^{\circ}$ it was assumed that deformation occurring in the inclined regions is a simple shear and uniform. In this regard, the plastic strain introduced by shearing was 
calculated simply by equation $\gamma=\operatorname{tg}(\theta)$, where $\theta$ is a inclination angle as shown in Fig. 1. This assumption leads to uniform plastic strain distribution after each $4 n(n=1,2, \ldots)$ deformation step. Fig. 4 shows the simulated distribution of equivalent plastic strain in sample after pressing and flattening steps. Inspection of this figure reveals that after $4 \mathrm{n}$ pass, the imposed plastic strain on material is not uniform. Also the material between inclined parts of grooved die is deformed by shearing during pressing (the 1st step) and material between flat parts of die remains almost unreformed. As can be seen in this figure, the plastic strain distribution at inclined regions (the 1st step) is not uniform. This inhomogeneous distribution of strain at these regions finally (after every $4 \mathrm{n}$ steps) leads to an inhomogeneity in imposed plastic strain.

After first pressing (the 1st step) the imposed strain is inhomogeneous because only materials at inclined regions are subjected to severe deformation but regions between flat parts of die receive low plastic deformation. After 2 nd step the inhomogeneity increases because the same regions are deformed during flattening. Before imposing 2 nd step the plate is shifted one groove length to left or right and consequently during the 3rd and the 4th step the unreformed regions (during the 1st and the 2nd step) are subjected to severe deformation. This leads to improvement of plastic strain distribution in sample. Hence at every deformation cycle (each cycle comprises 4 steps), first pressing and flattening increase the inhomogeneity but second pressing and flattening improve the strain distribution.
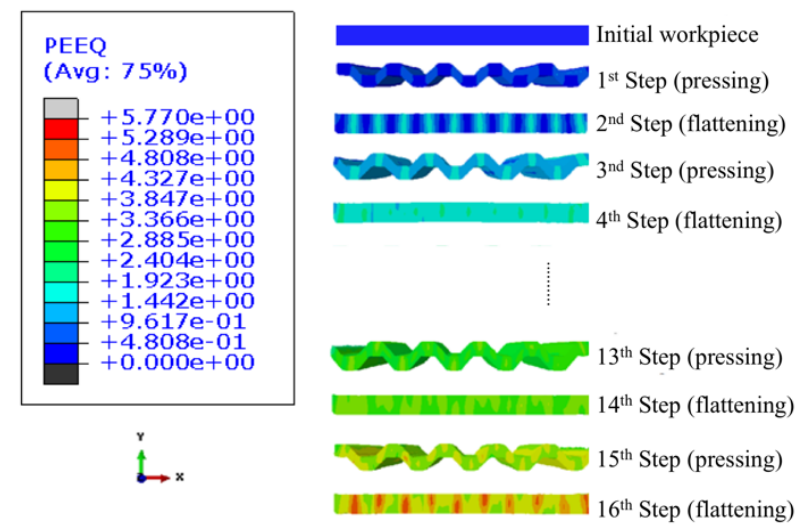

Fig. 4 Equivalent plastic strain distribution in workpiece deformed up to 16 pressings

Analysing the microstructure by TEM in flat top (undeformed 1 area) the structure after first pressing consisted of elongated and/or equiaxed subbubgrains segmented by dislocatios. The presence of subgrains and dislocation cells substructure is evidence that in this region has this region has also undergone quite a large amount of plastic deformation and it can not be denoted as an "undeformed" area (Fig. 5 (a)). Observation over wide areas of the structure (flat area 1 and sheared 2 area) suggests that dislocation activities concerning the formation of low angle subgrain boundaries were already effective at he time of the first pressing. The detail of such transition where more distinctive low angle boundaries are apparent can be seen in Fig. 5. The development of a deformed substructure in the sheared area after completing the pressing and flattening process $(\varepsilon \sim 4.5)$ is illustrated in Fig. 5. The microstructure consists of a banded arrangement of elongated subgrains, inside with dense dislocation network. Surprisingly, the small nuclei of polygonized subgrains were found along banded-like subgrains. A formation of polygonized dislocation-free 
subgrains, after some cycles pressings and flattenings using tools (Fig. 3) is not common to find them in deformed structure.

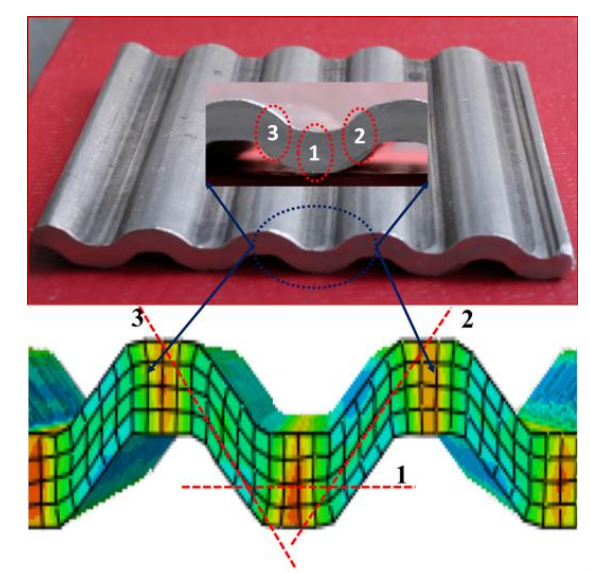

(a)

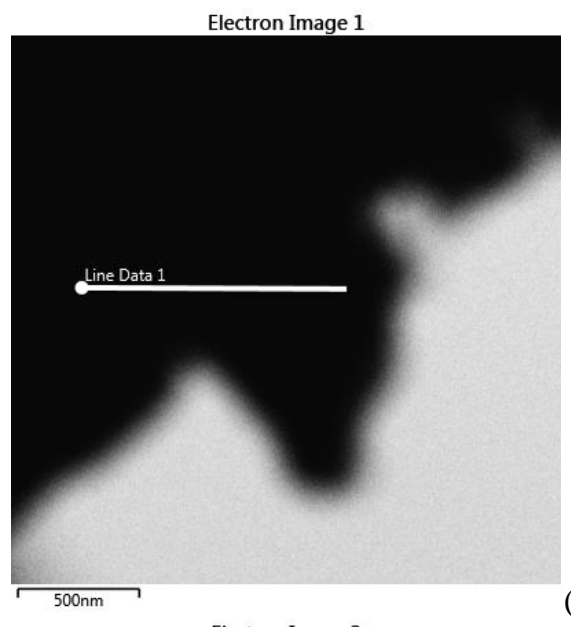

(b)
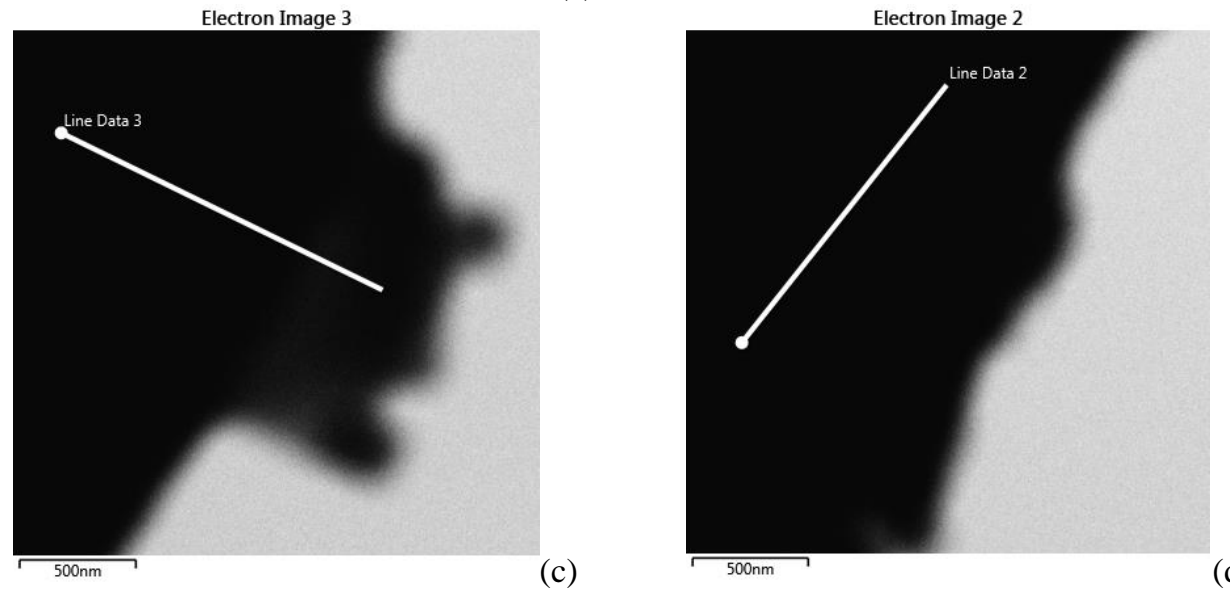

(d)

Fig. 5 The mixture of subgrain structure within deformation bands

Completing the first deformation cycle, the cumulative strain becomes $\varepsilon_{\text {eff }} \sim 1.12$ throughout the sample. The fragmentation of subgrains is apparent as well. The formation of new equi- axed "grains", deposisited along the subgrains was observed inside of deformed structure. The interior of these new grains is free of dislocations; grain boundaries are straight and they have a similar morphology to the already polygonized subgrains. The polygonization process is observed in AZ31 due to more intense plastic straining. The dislocation structure recovery and formation of polygonized grains was observed as a local process, which can be attributed also. When more intense straining was imposed the structural characteristics were similar, no matter whether four ( $\varepsilon_{\text {eff }} \sim 3.6$ ) or eight passes $\left(\varepsilon_{\text {eff }} \sim 4.5\right.$ ) were conducted. In the severely deformed areas the (banded) structure with mixture of deformation subgrains with high dislocation network and well developed polygonized subgrains were found (Fig. 5). The dislocation recovery effectively proceeds and dislocation annihilation is particularly evident. Locally observed, the more advanced process of polygonization contributed to formation of regular equiaxed subgrains free of dislocations. These 
can then be the nuclei of new grains with high angle (Fig. 5). The arreas with polygonized were observed more frequently as strain increased. Considering transformation characteristics in the deformed structure, it appears that the mechanism, which becomes effective for microstructure refinement, involving grain subdivision and transformation of deformed subgrains to polygonized ones within shear bands, is local dynamic recovery and is not caused due to more advanced microshearing.

\section{Conclusions}

Deformation inhomogeneity was studied in term of plastic strain distribution during deformation. It was found that after first pressing and flattening steps, the plastic strain is inhomogeneous but second pressing and flattening improve deformation distribution considerably.

On the other hand, deformation heterogeneity distribution developed in plate by applying CGP caused the evolution of a non-uniform microstructure. The TEM microstructure analysis results provided clear evidence that across the plate both the banded deformed microstructure where dislocation cell structure and/or partially or fully recovered polygonized subgrain microstructure are present. The dynamic recovery and local polygonization process contributes significantly to the formation of UFG microstructure. TEM microstructure analysis results indicate that there is a very low fraction of submicron grains with high angle grain boundaries even in case the strain applied is the highest.

\section{References}

[1] Y. Kojima: Materials Transaction, Vol. 42, 2001, p. 1154-1159, DOI: $10.2320 /$ matertrans.42.1154

[2] A. Mwembela, E. B. Konopleva, H. J. McQueen: Scripta Materialia, Vol. 37, 1997, p. 1789 -1795, DOI: 10.1016/S1359-6462(97)00344-8

[3] S. Schumann, H. Friedrich: Materials Science Forum, Vol. 419-420, 2003, p. 51-56, DOI: 10.4028/www.scientific.net/MSF.419-422.51

[4] S. R. Agnew, O. Duygulu: International Journal of Plasticity, Vol. 21, 2005, p. 1161-1193, DOI: 10.1016/j.ijplas.2004.05.018

[5] M. R. Barnett: Journal of Light Metals, Vol. 1, 2001, p. 167-177, DOI: 10.1016/S14715317(01)00010-4

[6] R. Z. Valiev et. al.: Journal of The Minerals, Metals and Materials Society, Vol. 58, 2006, No. 4, p. 33-39, DOI: 10.1007/s11837-006-0213-7

[7] Bidulská et al.: Chemicke Listy, Vol. 105, 2011, No. 16, p. 471-473

[8] J. Bidulská, T. Kvačkaj, I. Pokorny, R. Bidulský, M. A. Grande: Archives of Metallurgy a Materials, Vol. 58, 2001, No. 2, p. 371-375, DOI: 10.2478/amm-2013-0002

[9] Y. T. Zhu, T. G. Langdon: The Journal of The Minerals, Metals \& Materials Society, Vol. 56, 2004, No. 10, p. 57-63, DOI: 10.1007/s11837-004-0294-0

[10]R. Z. Valiev, R. K. Islamgaliev, I. V. Alexandrov: Progress in Materials Science, Vol. 45, No. 2, 2000, p. 103-189, DOI: 10.1016/S0079-6425(99)00007-9

[11]T. Kvačkaj et al: Archives of Metallurgy a Materials, Vol. 58, 2013, No. 2, p. 407-412, DOI: 10.2478/amm-2013-0008

[12] A. P. Zhilyaev, T. G. Langdon: Progress in Materials Science, Vol. 53, 2008, p. 893-979, DOI:10.1016/j.pmatsci.2008.03.002 
[13]Y. T. Zhu, T. C. Lowe, H. Jiang, J. Huang: Patent No. 6197129, USA, 2001

[14] Y. T. Zhu, H. Jiang, J. Huang, T. C. Lowe: Metallurgical and Materials Transactions A, Vol. 32, 2001, p. 1559-1562, DOI: 10.1007/s11661-001-0245-0

[15]T. C. Lowe, R. Z. Valiev: JOM, Vol. 56, 2004, No. 10, p. 64-77, DOI: 10.1007/s11837-0040295

[16] A. Azushima et al.: CIRP Annals-Manufacturing Technology, Vol. 57, 2008, No. 2, p. 716-735, DOI: 10.1016/j.cirp.2008.09.005

[17]L. Olejnik, A. Rosochowski: Technical Science, Vol. 53, 2005, No. 4, p. 413-423

[18] R. Z. Valiev, T. G. Langdon: Progress in Materials Science, Vol. 51, 2006, No. 7, p. 881-981, DOI: 10.1016/j.pmatsci.2006.02.003

[19] Abaqus/CAE, Hibbit, Karlsson \& Sorensen, Inc 2010, USA

[20] Abaqus/Theory Manual, Hibbit, Karlsson \& Sorensen, Inc 2010, USA

\section{Acknowledgements}

Authors are grateful for the support by the B2016-BKA-26 project funded by the the Ministry of Education and Training of the Vietnam. 